\title{
MACEDONIO FERNÁNDEZ Y WITOLD GOMBROWICZ: LOS NO-EXISTENTES NOVELISTAS
}

\author{
Macedonio Fernández and Witold Gombrowicz: the non-existing novelists
}

Elizabeth Corrales Millán*

\begin{abstract}
RESUMEN
En general, la historiografía literaria ha relacionado al Museo de la Novela de la Eterna de Macedonio Fernández y a Ferdydurke de Witold Gombrowicz de manera espacial (como parte de la producción argentina, incluso en el caso del polaco Gombrowicz) y temporal (sus periodos de producción son más o menos coincidentes). No obstante, uno de sus rasgos vinculatorios más importantes y menos estudiados es su inserción en el marco general de la estética de las vanguardias durante la primera mitad del siglo XX. En este sentido, si bien el Museo se tiene por un texto representativo de la novela hispanoamericana de vanguardia, a Ferdydurke no se le considera como parte de esta clasificación. De lo anterior se desprende mi propósito en este trabajo: subrayar que el Museo y la traducción al español de Ferdydurke - hecha por el propio Gombrowicz durante su exilio en Argentina- comparten rasgos contrapuestos al canon novelístico predominante, incluido el de las vanguardias hispanoamericanas, así como proyectos poéticos subversivos y antiformales de corte radical, que reúnen a ambas obras en una convergencia exclusiva con distintas expresiones artísticas de vanguardia, en un intercambio que trasciende cualquier ámbito nacional.

Palabras clave: novela hispanoamericana de vanguardia, metaficción, vanguardias históricas, canon, arte abstracto.
\end{abstract}

ABSTRACT

In general, literary historiography has related Macedonio Fernandez's The Museum of Eterna's Novel and Witold Gombrowicz's Ferdydurke spatially (as part of Argentina's production, even in the case of the Polish Gombrowicz) and temporally (their production periods are more or less coincident). However, one of its most important and least studied linking features is its insertion in the general setting of the avant-garde aesthetics during the first half of the twentieth century. In this sense, although The Museum is considered as a representative text of the Hispanic American avant-garde novel, Ferdydurke is not considered as part of this classification. From the above it follows my purpose in this paper: emphasize that The Museum and the Spanish translation of Ferdydurke — made by Gombrowicz himself during his exile in Argentina — share pitted traits against the prevailing novelistic canon, including the Hispanic American avant-garde movements, as well as antiformal, subversive and radical poetic projects that bring together both works in an exclusive convergence with diverse avant-garde artistic expression, in an exchange that transcends any national level. Key Words: Hispanic American avant-garde novel, metafiction, historic avant-garde, canon, abstract art.

Universidad Veracruzana. Doctorado en Literatura Hispanoamericana. Instituto de Investigaciones Lingüístico-

Literarias. México.

Correo electrónico: lilith.rei@gmail.com

Recepción: 14/7/16. Aceptación: 12/8/16. 


\section{El corpus vanguardista hispanoamericano}

En la historia de las letras hispanoamericanas y de la literatura contemporánea, tanto Museo de la Novela de la Eterna de Macedonio Fernández como Ferdydurke de Witold Gombrowicz se han posicionado como sólidos ejemplos de poéticas marginales, anticanónicas y cuasi aisladas (Sábato 1983: 7-13) incluso en un contexto de suyo renovador para el arte como el de principios del siglo XX. En el caso de Macedonio, si bien se trata del "abuelo de la vanguardia", el "Quevedo criollo", e incluso un "semidiós" (García 2003: 38; Oviedo 2001: 298-305; Borges 1993: 12), no pertenece propiamente al martinfierrismo o al ultraísmo, aunque se relacionara con estos grupos en uno $\mathrm{u}$ otro aspecto. En palabras de José Miguel Oviedo, "lo que [Macedonio] traía a la escena literaria era algo realmente original, anómalo, excéntrico e inclasificable: él era su propia vanguardia, distinta de todas las otras" (2001: 298-299). En cuanto a Gombrowicz, prácticamente permaneció en el anonimato durante los veintitrés años y 266 días que vivió en Argentina, y no fue sino hasta los años sesenta que comenzó su "rehabilitación" literaria en tierra porteña (Freixa Terradas 2008: 82-85). El intercambio que tuvo con los círculos de la vanguardia argentina de los años treinta ha sido ampliamente comentado en un sentido negativo: Gombrowicz no fue bien recibido por los epígonos del martinfierrismo ni del ultraísmo, ya fuera por su personalidad de aristócrata excéntrico o por supuestas desavenencias artísticas (Gombrowicz 2005: 80). En 1947, la revista Sur de Victoria Ocampo, heredera de las vanguardias mencionadas, rechazó publicar un fragmento de Ferdydurke (Freixa Terradas 2008: 47-53), recién traducido al español por el propio polaco y un grupo de escritores amigos del personaje-autor.

Así comienza la historia de los cruces entre la obra macedoniana y gombrowicziana, cuyo origen podemos rastrear no sólo desde el parecido entre el español de Gombrowicz y el de Macedonio, oportunamente hallado por Ricardo Piglia (1987: 13-15), sino a partir de numerosos elementos estéticos que trascienden lo nacional, lo idiomático y lo lingüístico. La fragmentación, la inclusión de digresiones y comentarios en sus anti-narrativas, la reflexión sobre la obra en la propia obra - en particular sobre la forma artística-, son algunos de los puntos de encuentro entre ambos escritores. Me atrevo a aventurar que Adolfo y Jorge Fernández de Obieta, hijos de Macedonio, habrían coincidido con Piglia, y que fueran aquellos cruces el motivo de incluir el cuento "Filifor forrado de niño" - capítulos IV y V de Ferdydurke - en la revista de vanguardia Papeles de Buenos Aires (1943-1945), de la que Adolfo era editor y donde publicaron el propio Macedonio, Ramón Gómez de la Serna, Raúl Scalabrini Ortiz, Felisberto Hernández, Virgilio Piñera y Ernesto Sábato (González 2013: 12) —estos dos colaboradores en la traducción al español de Ferdydurke. (FIGURA 1.1.)

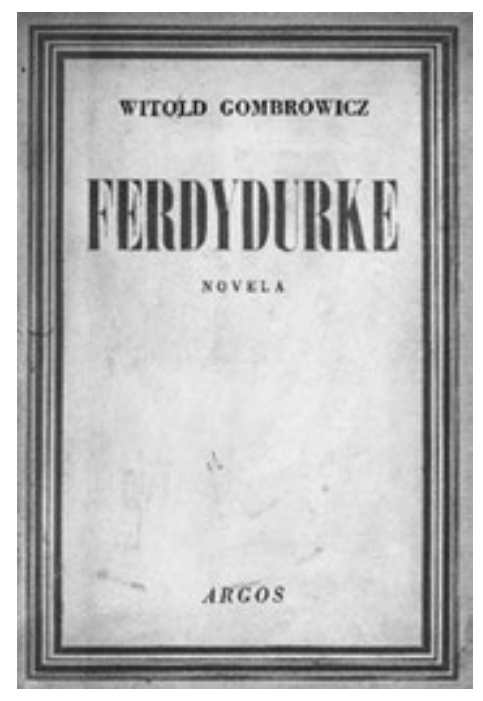

FIGURA 1.1.

Portada de la primera edición en español de Ferdydurke, 1947. 
Todo lo anterior arroja dos corolarios principales: 1) el lugar indiscutible de Macedonio en el parnaso de la literatura argentina - si bien poco se ha modificado su apreciación como precursor o prototipo de algo por venir, como él mismo habría previsto (Fernández 1996: 17-19)—; 2) la posición más o menos soslayada de Gombrowicz por parte de los herederos de las vanguardias argentinas de su contexto, y más o menos interlocutora de otras poéticas latinoamericanas como las de Piñera y Sábato. Así pues, las distintas recepciones contextuales de dos novelistas con propuestas estéticas convergentes, y que actualmente se consideran fundamentales en la historia de la literatura argentina, son aspectos que demuestran la necesidad de una valoración distinta del corpus reconocido como novela vanguardista hispanoamericana. Dicho corpus generalmente incluye a Vida del Ahorcado de Pablo Palacio; La señorita etc. (1922) y El café de nadie (1926), de Arqueles Vela; El habitante y su esperanza. Novela (1926), de Pablo Neruda; La casa de cartón (1927-28) de Martín Adán; La llama fría (1925) y Novela como nube (1928), de Gilberto Owen; las novelas de Vicente Huidobro, Roberto Arlt, Juan Emar, Gamaliel Churata y Adán Buenosayres (1948) de Leopoldo Marechal (Niemeyer 1998: 161). Cabe mencionar que aun cuando Vida del Ahorcado y Museo de la Novela de la Eterna se tienen por ejemplos paradigmáticos y fundadores de las vanguardias hispanoamericanas, Palacio y Macedonio jamás se adscribieron a movimientos literarios o signaron manifiesto alguno de manera explícita.

Por otra parte, la reciente incursión del concepto de novela vanguardista hispanoamericana en la crítica y la historiografía literarias puede ser, en buena medida, la razón de que el autor de Ferdydurke no esté considerado en los corpus de obras que integran dicho concepto. Frente a los abundantes estudios sobre la producción lírica de vanguardia, apenas en los años ochenta se empieza a reflexionar sobre la novela vanguardista hispanoamericana como género histórico que remite al periodo aproximado entre los años veinte y treinta del siglo $\mathrm{XX}$, caracterizado como un anti-discurso que cuestiona el sistema de discursos existente y provoca el orden sociocultural representado por el mismo sistema (Niemeyer 1998: 162). Esta caracterización como género histórico antidiscursivo necesariamente implica la consideración de un contexto abarcador, entre otras variables estéticas, de lo hispanoamericano y lo literario en cuanto a sus nexos con las vanguardias en distintas regiones.

\subsection{Autovanguardias}

Es en este cruce de variables donde se puede revisar la singularidad de textos como Ferdydurke y Museo de la Novela de la Eterna. A pesar de su exclusión o inclusión reservada en los directorios de vanguardias, es indudable que comparten con éstas una posición contestataria frente a las convenciones y los cánones artísticos. Sin embargo, la actitud de cuestionamiento hacia las formas del arte institucional de ambos autores es casi absoluta, por lo que alcanza

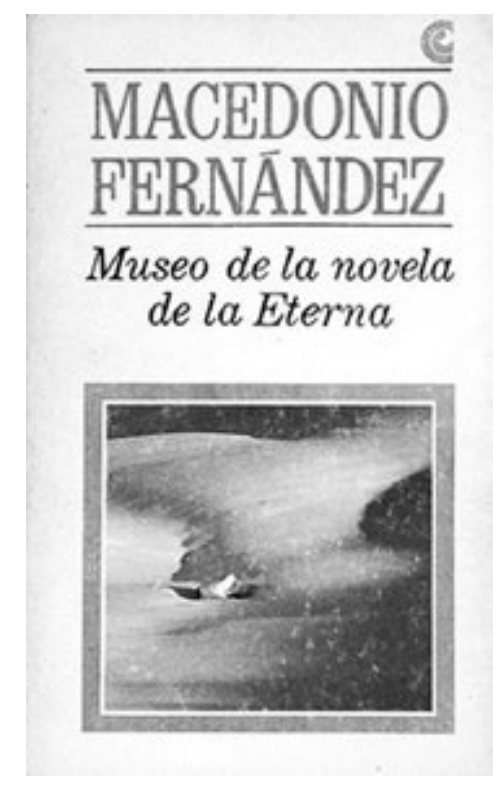

FIGURA 1.2.

Portada de la primera edición de Museo de la novela de la Eterna, 1967. 
tardíamente a los propios vanguardismos de principios de siglo para cuando Ferdydurke (1947) y el Museo (1967) se publican finalmente en Argentina (FIGURA 1.2). Por ejemplo, sobre las vanguardias polacas y argentinas, Gombrowicz comenta:

\begin{abstract}
Me acuerdo de aquellos extraños y mal pergeñados panfletos, escritos, manifiestos ridículos, versos entre revolucionarios y abortados, teorías grandilocuentes pero también grandiosamente cómicas y montones de volúmenes inevitables [...] todo eso era para mí la vanguardia. Esta producción era más o menos parecida en todas las ciudades civilizadas, y ahora, aquí, en la Argentina, también me encuentro en los cafés a viejos o menos viejos jovenzuelos pegados a la ubre de esta eterna madre [...] Desde entonces formaron parte de la literatura oficial y se convirtieron en burócratas del arte. (Gómez 2008: 99).
\end{abstract}

Macedonio y Gombrowicz demuestran un compromiso profundo, si bien implícito, con el cambio en los valores estéticos de las vanguardias históricas, pero en sus casos mediante un radicalismo y un escepticismo llevados hasta sus últimas consecuencias: Gombrowicz critica a las "tías culturales", metáfora de cualquier canon arraigado hacia la primera mitad del siglo XX, y Macedonio se muestra indiferente a publicar, se aísla de los círculos intelectuales de su tiempo y se mofa afectuosamente del círculo martinfierrista que lo tiene por padre fundador (Cf. Camblong 1996: XLI; Monegal 1974: 51-54). La preminencia en Museo y Ferdydurke del absurdo frente a lo lógico/racional, lo inacabado por lo acabado, el sueño por la vigilia, así como la voluntad de fragmento y equívoco es parte todavía de la crisis mimética que abanderaron con especial énfasis las primeras vanguardias pictóricas en Europa. En este punto es necesario aclarar, junto con Nelson Osorio, que las vanguardias hispanoamericanas no son un epifenómeno de los movimientos europeos, sino estéticas que dialogan con éstos desde su propia historicidad y espacialidad, en la coyuntura amplificante de la nueva organización mundial de la posguerra (1981: 227-232). Los movimientos de vanguardia en la América de habla hispana encabezan sus propios impulsos de subjetividad estética, compartidos dialógica y polémicamente con las vanguardias europeas.

La cuestión del tránsito de la vanguardia entre Europa y América y de las relaciones entre sus respectivos focos es interesante y muy reveladora de otro aspecto esencial del movimiento: el carácter auténticamente internacional de sus propuestas y de su lenguaje. La vanguardia habla todas las lenguas y aparece, con las naturales variantes, casi en cualquier parte - aún más allá del mundo occidental - y casi en el mismo momento: desde mediados de la primera década del siglo XX hasta más o menos el comienzo de los años treinta, en los que sufre una transformación o una renovación. (Oviedo 2001: 291).

Un segundo periodo de la vanguardia hispanoamericana, según José Miguel Oviedo, tendría lugar después del Segundo Manifiesto Surrealista de Breton (1929) y aproximadamente hasta finales de los años cincuenta (2001: 289467). Ambos periodos cubren tanto la escritura del Ferdydurke original y su traducción en Argentina como los borradores completos de Museo. Sin embargo - más allá de su difusión histórica-, el privilegio radical de Macedonio y Gombrowicz por lo anti y lo contra, incluso frente a movimientos de "arte nuevo" de su contexto, manifiesta una voluntad de diferenciación total que los condujo a extender sus propuestas artísticas hacia cualquier ámbito estético institucionalizado. Coinciden así con el espíritu de la vanguardia en su sentido más amplio, que consiste en "el intento de devolver a la práctica la experiencia estética (opuesta a la praxis vital) que creó el esteticismo", es decir, "aquello que más incomoda a la sociedad burguesa, ordenada por la racionalidad de los fines, debe convertirse en principio organizativo de la existencia" (Burger 2000: 81). En Macedonio, este intento se extiende al punto de que no publica en vida su Novela de la Eterna, anunciada desde 1928, sino que deja instrucciones a Adolfo de Obieta para el efecto, pues se trata de la novela siempre prometida por su autor. En "Al que quiera escribir esta novela (Prólogo final)" de Museo, establece una suerte de testamento: entre el imaginador (autor) y el imaginado (personaje), 
que la imaginación sea la síntesis de ambos en la figura del futuro lector de la novela.

Dejo, así, dados la teoría perfecta de la novela, una imperfecta pieza de ejecución de ella y un perfecto plan de su ejecución. Nótese que hay un verdadero éxito mío en el adosamiento de la doble trama [...] la artificiosidad más fecunda para la conciencia en su efecto de fragilizar la noción y certeza de ser, de las cuales procede la universal intimidación de la igualmente absurda y vacua noción verbal del no-ser. No hay más que un no-ser: el del personaje, el de la fantasía, de lo imaginado. El imaginador no conocerá nunca el no ser. (Fernández 1996: 254).

\section{La esfera del "entre"}

Uno de los primeros objetivos reconocibles en estas poéticas es el desdibujamiento de todo límite. Los esquemas, los rótulos, los conceptos, aprisionan al yo, lo determinan, lo deforman (FIGURA 2.1). ¿Cómo descubrir primero lo que está detrás de palabras y formas básicas, antes de que el concepto se imponga en nuestra mente y la aprisione? ¿No es esto, a su vez, una conceptualización previamente dada, que presupone un yo en estado de pureza?

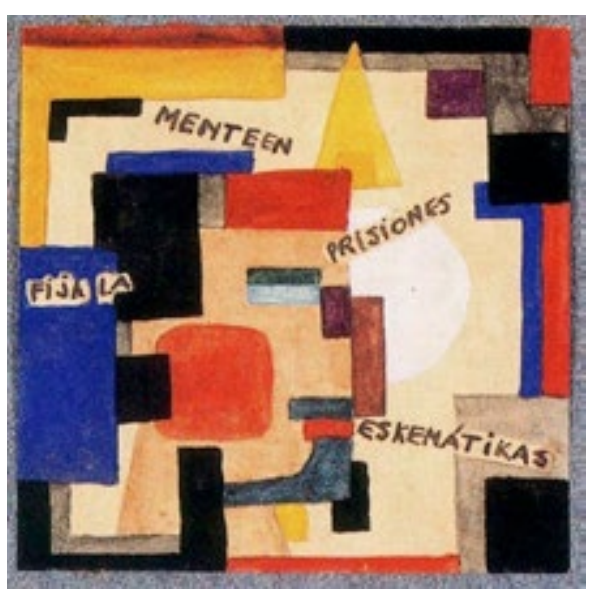

FIGURA 2.1.

Fija la menteen prisiones eskemátikas, Xul Solar, 1919.

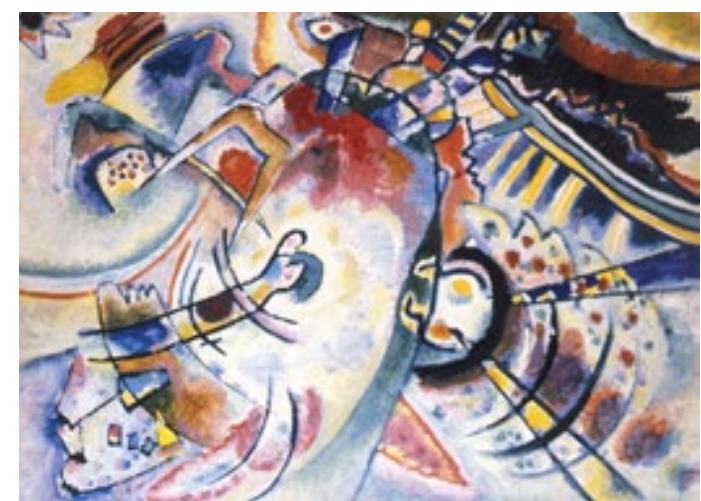

FIGURA 2.2.

Sin título, Kandinsky, 1916.

Asumir este sentido de la contradicción, criticar el mundo de lo abstracto que finge lo concreto desde la propia abstracción, son actitudes que corresponden con el propósito de las vanguardias de contravenir el arte burgués desde objetivaciones artísticas burguesas. En lugar de soslayar ésta u otras contradicciones, tanto Macedonio como Gombrowicz las asumen como eje principal de sus poéticas de lo absurdo/ ilógico. El autor de Museo de la Novela de la Eterna elabora con este fin su propuesta de Belarte Conciencial:

En mi ansiedad antigua por un arte puro, por una perfección de no realismo, me he encontrado con esta definición última: Sólo es belarte aquella obra de la inteligencia que se proponga [...] la conmoción del ser de la conciencia en un todo, y que para ello no se valga nunca de raciocinios. [...] en la que yo llamo Ilógica del Arte o Humorística Conceptual, el desbaratamiento de todos los guardianes intelectivos en la mente del lector por la creencia en lo absurdo que ella obtiene por un momento, lo liberta definitivamente de la fe en la lógica [...] esa lógica que nos dice todos los días: "puesto que todos mueren, tú has de morir", o "no hay efecto sin causa". (Fernández 1990: 286, 303).

En la estética macedoniana, todo arte verdadero debe ser antimimético (1996: 39-40). La suscitación indirecta de estados emocionales que denomina Belarte se puede alcanzar siempre 
y cuando los asuntos o temas se reduzcan a pretextos para hacer operar "la Versión o Técnica" de la obra artística. En el prólogo de Museo titulado "Perspectiva", Macedonio describe su técnica de novelar como formas fragmentarias para plasmar su teoría de la novela. No importa, pues, de qué trate esta última, sino que cada una de sus partes sea concebida como una totalidad espaciotemporal por el lector: "Novela cuyas incoherencias de relato están zurcidas con cortes horizontales que muestran lo que a cada instante hacen todos los personajes de la novela" (1996: 9. Subrayado mío). (FIGURA 2.2. y 2.3.)

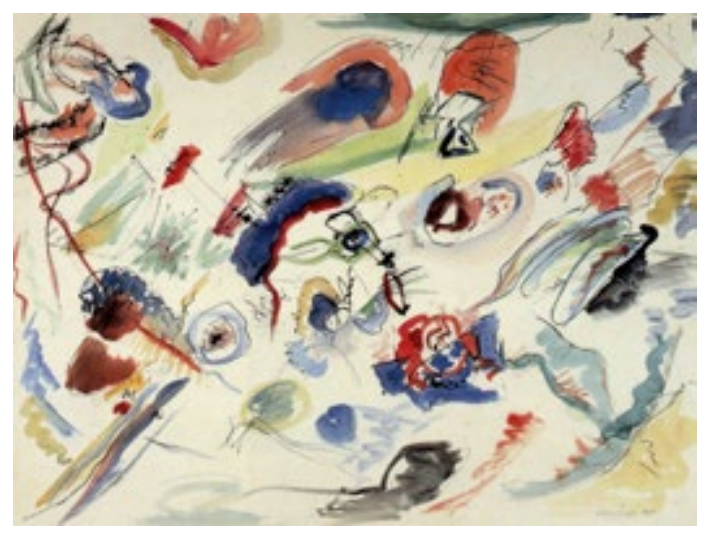

FIGURA 2.3.

Primera Acuarela Abstracta, Kandinsky, 1910.

Este ethos que anula el dominio temático o del contenido (Bermúdez Martínez 2001: 40) en beneficio de la forma artística lo comparten las primeras escuelas de arte abstracto, el suprematismo, el neoplasticismo, el rayonismo, el cubofuturismo y el purismo, entre otras vanguardias pictóricas de las primeras décadas del siglo XX:

(...) la idea constructiva de la forma vanguardista, frente a la matriz compositiva de la obra de arte clásica, hace histórica y estéticamente singular su renuncia a la figuratividad; construcción entendida como producción artificial de una forma que objetiva un sistema de relaciones implícitas. La vanguardia construye su forma a partir de unidades que no son entidades físicas sino relaciones conceptuales... [Se trata de] negar la objetividad en favor de la estructura entendida como sistema de relaciones interiores a la obra (Piñón 2000: 17). (FIGURA 2.4.)

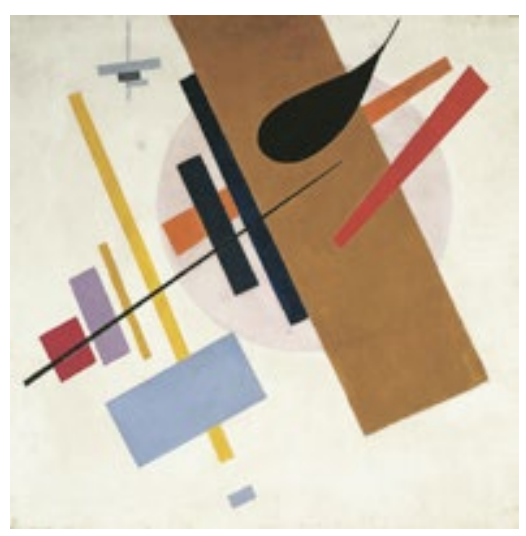

FIGURA 2.4

Supremus no. 55, Malevich, 1916.

En Ferdydurke y Museo de la Novela de la Eterna se establecen ostensible y explícitamente - a diferencia de otras novelas de corte vanguardista - la preocupación por la relación forma/fondo y otros problemas estéticos que, de acuerdo con sus horizontes de pensamiento, deben ser resueltos en el arte: ¿quién es "yo", su forma e identidad? ¿Cómo distinguir el sueño de la vigilia, y dentro de esa distinción, la ficción de la realidad? ¿Puede ser la existencia que llamamos "vida" una de varias realidades, y no la realidad "real”? ¿Qué es el arte? ¿Puede el arte crear y no sólo representar? Gombrowicz dirá que la forma nos construye en nuestras visiones del mundo, y a la vez, construimos la forma a partir de éstas. La lucha de las vanguardias contra las formas clásicas del arte trata de generar modalidades de expresión propias que, innegable y trágicamente en un sentido gombrowicziano, hereda y comparte con el resto de los buscadores de la autonomía artística. 
Por fin, ¿somos nosotros los que creamos la forma o más bien es ella la que nos crea? [...] el ser humano no se exterioriza de modo inmediato y concordante con su naturaleza, sino siempre en una definida forma; y [...] esta forma, aquel estilo, modo de ser, modo de hablar y reaccionar, no proviene sólo de él, sino que le es impuesto desde el exterior, y he aquí que ese mismo hombre puede manifestarse por afuera, ora sabia, ora tontamente, sanguinaria o angélicamente, madura o inmaduramente según qué forma, qué estilo se le presente, y cómo esté presionado y limitado por el prójimo (Gombrowicz 1983: 72, 79).

Más allá de un extrañamiento o una "desautomatización de la percepción" como el que establecían los postulados formalistas en paralelo con las vanguardias, el propósito común de Gombrowicz, Macedonio y el ethos vanguardista pleno consiste en resignificar el fragmento y su percepción, es decir, aquello inacabado, inmaduro, anticipaciones intra o extratextuales del texto prometido, el casi-adulto, el casi-novelista dentro y fuera de la novela. En las escrituras fragmentarias del porteño y el polaco, esto se logra borrando las barreras ficcionales y minando las formas impuestas desde la cultura. (FIGURA 2.5.)
Esas, pues, son las fundamentales, capitales y filosóficas razones que me indujeron a edificar la obra sobre la base de partes sueltas - conceptuando la obra como una partícula de la obra- y tratando al hombre como una fusión de partes de cuerpo y partes de alma, mientras a la Humanidad entera la trato como a una mezcla de partes. Pero si alguien me hiciese tal objeción: que esta parcial concepción mía no es, en verdad, ninguna concepción, sino una mofa, chanza, fisga y engaño, y que yo, en vez de sujetarme a las severas reglas y cánones del Arte, estoy intentando burlarlas por medio de irresponsables chungas, zumbas y muecas, contestaría que sí, que es cierto, que justamente tales son mis propósitos (Gombrowicz 1983: 72-73).

Ferdydurke constituye, pues, la búsqueda de la identidad propia en el borde de la forma y lo amorfo, mientras que el Museo es el encuentro del sí mismo en el borde del Yo y del Otro. En última instancia, la misión de ambas escrituras consiste en modificar el estatuto de la alteridad mediante lo estético. Para Gombrowicz, aquel borde o esfera del "entre" "es un fermentario incesante de formas, estilos de ser, aparatos de dominación, dioses, ideologías, mitos de redención capaces de engendrar las más sublimes pero también las más atroces deformidades de la condición humana” (Rússovich 2011: párrafo 21). (FIGURA 2.6.)

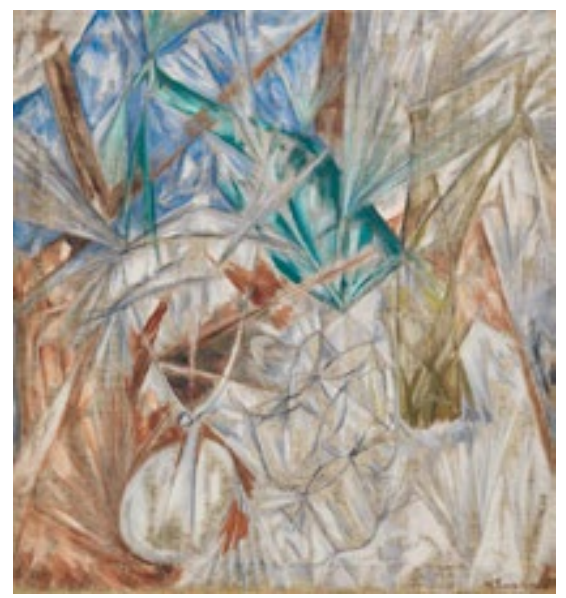

FIGURA 2.6. 
Comprenderá el hijo de la tierra que él no se expresa en armonía con su ser verdadero sino siempre en forma artificial y dolorosamente impuesta desde el exterior, ora por otros hombres, ora por las circunstancias. Empezará entonces a temer aquella forma suya y a avergonzarse de ella así como hasta ahora se glorificaba y se consolidaba en ella. Pronto empezaremos a temer a nuestras personas y personalidades porque sabremos que esas personas no son del todo nuestras [...] Grandes descubrimientos se necesitan [...] para que el hombre se salve de su rigidez exterior y logre reconciliar mejor el orden y el desorden, la forma y lo informe, la madurez y la inmadurez eterna y santa (Gombrowicz 1983: 84-85).

\subsection{Esto no es un yo}

La misión vanguardista de Gombrowicz también consiste en movilizar el camino de la ambigüedad entre lo subjetivo y lo objetivo con el fin de irritar, conmocionar, provocar a los modelos de mayor raigambre en la alta cultura. La forma ya no someterá al contenido, el significante al significado, y viceversa, como aquellos colores que desbordan los continentes en (in)determinada manifestación de emociones (FIGURA 2.7).

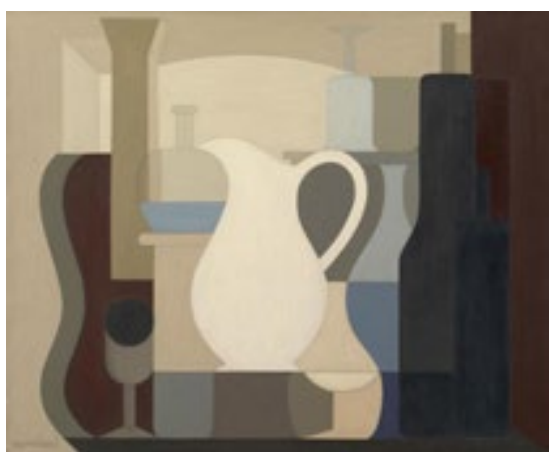

FIGURA 2.7.

La jarra blanca, Ozenfant, 1926.

Sólo en este horizonte no impositivo del "entre" cobran sentido las preocupaciones estéticas de ambos escritores. En su caso,
Gombrowicz parte de reducciones al absurdo que conducen al lector a cuestionarse radicalmente y a enfrentarse con el ridículo de lo convencional, en extremos grotescos que, jerarquizados por la institución del arte, resultan perfectamente aceptables.

¿Y por qué una autora que pone su dedo heroico en las más sangrientas heridas sociales, describiendo sin temor la muerte por hambre de una familia obrera, compuesta de seis o diez personas, por qué, pregunto, ella nunca se atrevería a hurgarse el oído en público con el mismo dedo? Porque esto sería mucho más terrible (Gombrowicz 1983: 138).

A semejanza del dadaísmo, el surrealismo y el expresionismo, Gombrowicz traslada al primer plano aquello despreciado por la institucionalidad.

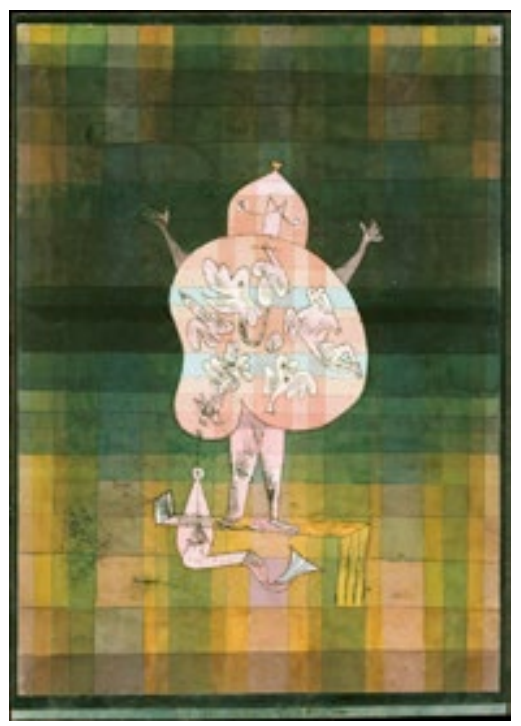

FIGURA 2.8.

Ventrílocuo y pregonero en el moro, Klee, 1923.

En este sentido, reivindica - como la estética surrealista - la imaginería de las primeras etapas de la vida, que considera más diversa, amplia y libre en comparación con las restricciones de la vida adulta; el sentido 
del absurdo y la maravilla será mayor entre la juventud, y por tanto, algo que el arte debería perseguir también (FIGURA 2.8). Se trata de subvertir el mundo de las estructuras ordenadas mediante un ataque irracional y chocante. Dado que la irracionalidad no tiene una forma fija, puede ayudar en la construcción de puentes que escapen a las convenciones del tiempo y el espacio, como sucede en las ensoñaciones.

[...] el sueño destruye la realidad del día vivido, extrae de ella unas migajas, unos fragmentos extraños, y los compone absurdamente en un dibujo arbitrario; pero para nosotros este absurdo constituye justamente el sentido más profundo; [...] De modo que el arte también puede y debería destruir la realidad, descomponerla en elementos, construir de ellos nuevos mundos absurdos; en esta arbitrariedad se esconde una ley, la transgresión del sentido tiene su sentido, la locura, al destruirnos el sentido exterior, nos introduce en nuestro sentido interior (Gombrowicz 2005: 266). (FIGURA 2.9.)

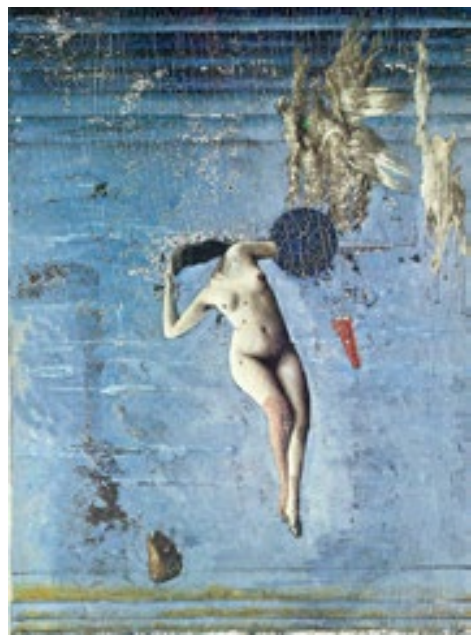

FIGURA 2.9.

La pubertad cercana a las pléyades, Ernst, 1921.

Por su parte, Macedonio concurre con el surrealismo en la denuncia de la imposibilidad y, por tanto, futilidad representacional, en beneficio de la construcción verdaderamente artística. Si las palabras y las cosas, como señala Foucault, no tienen una relación de correspondencia sino de distancia (1984: 7), para Macedonio resulta de poco provecho tratar de reunirlas en el horizonte del "como sí" que resultará, en cualquier caso, artificial. En cambio, el arte debe cultivar la transparencia de lo nombrado y lo que nombra, de lo verosímil y lo inverosímil reunidos en un instante de conmoción de la conciencia. "Yo quiero que el lector sepa siempre que está leyendo una novela y no viendo un vivir, no presenciando "vida"' (Fernández 1996: 37). Como el surrealista Magritte en La traición de las imágenes (FIGURA 2.10), Macedonio designa buena parte de los elementos de su poética en un sentido negativo: su novela es el "Hogar de la no existencia" en que necesita hallarse "Deunamor, el No Existente Caballero" (1996: 22), de modo que en todo momento prevalezca el sentido de la ficción, así como la certeza de que la riqueza y las posibilidades de la realidad vital no se pueden representar (1990: 236).

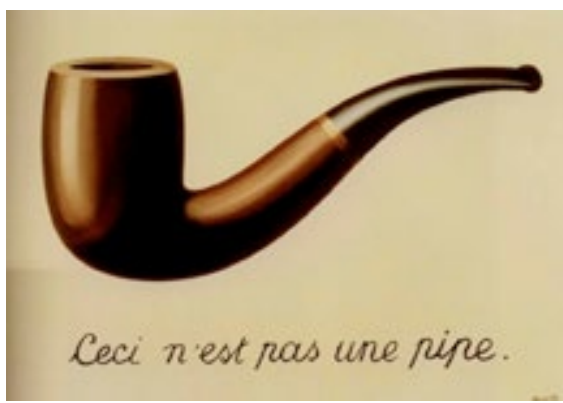

FIGURA 2.10.

La traición de las imágenes, Magritte, 1929.

Con el mismo propósito que Magritte al escribir "Ceci n'est pas une pipe" como rótulo de la imagen de una pipa, en Museo de la Novela de la Eterna Macedonio proclama reiteradamente la irrealidad de su casi-novela e impide que el lector tenga momentos alucinatorios: esto no es una vida, mientras que en Ferdydurke Gombrowicz secundará: esto no soy yo.

Esta autoafirmación negativa — si cabe el oxímoron-, las características que ambos textos 
comparten con el corpus de obras y novelas reconocido como vanguardista —en particular la necesidad de una constante reformulación de sus marcas de novedad e iconoclastia frente a los modelos canónicos-, así como su génesis durante el proceso de los movimientos de vanguardia europeos e hispanoamericanos y sus intercambios estéticos con estos, son elementos que abren la posibilidad de considerar a Museo... y a Ferdydurke en español como parte del corpus señalado y proponer una reconfiguración de la historia literaria a partir de esta inclusión, de manera que no se establezcan como determinantes de tiempo y espacio aquellas centradas en una perspectiva unívoca de lo nacional, especialmente si se tiene en cuenta desdibujamiento de las fronteras nacionales y el aumento de los fenómenos migratorios en la globalización. En este sentido, Gombrowicz fue precursor de una suerte de esperanto literario, un lenguaje cuyo código es la literatura global, y que en esta intención de lo humano en búsqueda de lo humano coincide con la posibilidad de la no identidad, origen o pasado de la metaficción macedoniana.

\section{Bibliografía}

Bermúdez Martínez, María. 2001. La incertidumbre de lo real: bases de la narrativa de Juan José Saer. Oviedo: Departamento de Filología Española, Universidad de Oviedo.

Borges, Jorge Luis. 1993. El tamaño de mi esperanza. Buenos Aires: Seix Barral.

Burger, Peter. 2000. Teoría de la Vanguardia. Barcelona: Península.

Camblong, Ana María. 1996. "Estudio preliminar". En: Museo de la Novela de la Eterna. Edición Crítica: XLI.

Corral, Rose (ed.). 2006. Ficciones limitrofes. Seis estudios sobre narrativa hispanoamericana de vanguardia. México: Centro de Estudios Lingüísticos y Literarios, El Colegio de México.

Fernández, Macedonio. 1996. Museo de la Novela de la Eterna. Edición Crítica (Ana María Camblong y Adolfo de Obieta, coords.). $2^{\mathrm{a}}$ ed. Madrid, París, Buenos Aires, Sao Paulo, Río de Janeiro, Lima: Archivos de la Literatura Latinoamericana, del Caribe y Africana XX/Fondo de Cultura Económica/Unesco.

Fernández, Macedonio. 1990. Teorías. Buenos Aires: Corregidor.

Freixa Terradas, Pau. 2008. Recepción de la obra de Witold Gombrowicz en la Argentina y configuración de su imagen en el imaginario cultural argentino. Tesis doctoral. Universidad de Barcelona.

Foucault, Michel. 1984. Las palabras y las cosas. México: Siglo XXI.

García, Carlos (comp.). 2003. Correspondencia Macedonio-Borges, 1922-1939. Buenos Aires: Corregidor.

Gombrowicz, Witold. 2005. Diario (1953-1969). Barcelona: Seix Barral.

Gombrowicz, Witold. 1983. Ferdydurke. Buenos Aires: Sudamericana.

Gómez, Juan Carlos. 2004. Gombrowicz, este hombre me causa problemas. Buenos Aires: Interzona.

Gómez, Juan Carlos. 2008. Gombrowiczidas \#34. Buenos Aires: El Ortiba. Recuperado de http://www.elortiba.org/gombr2.html. [Consulta: 31 de marzo de 2016].

González, Horacio. 2013. "Sobre la necesidad de publicar estos 'Papeles"'. En: Obieta, 
Adolfo de (ed.). Papeles de Buenos Aires: 11.

Jitrik, Noé. 2007. Historia crítica de la literatura argentina: Macedonio. T. 7. Buenos Aires: Emecé.

Kamenszain, Tamara. 1976. "Los que conocieron a Gombrowicz". En: Texto crítico IV: 89-105.

Lafleur, Héctor René, Sergio D. Provenzano y Fernando P. Alonso. 1968. Las revistas literarias argentinas, 1893-1967. $2^{\mathrm{a}} \mathrm{Ed}$. Buenos Aires: Centro Editor América Latina.

Monegal, Emir Rodríguez. 1974. Narradores de esta América. T. 2. Buenos Aires: Alfa.

Niemeyer, Katharina. 1995. "Acercamiento a la novela vanguardista hispanoamericana". En: Odber de Baubeta, Patricia Anne (coord.). Actas del XII Congreso de la Asociación Internacional de Hispanistas. Tomo VII. Estudios Hispanoamericanos II: $161-169$.

Obieta, Adolfo de. 1999. Macedonio Fernández. Memorias errantes. Buenos Aires: Corregidor.

Odber de Baubeta, Patricia Anne (coord.). 1998. Actas del XII Congreso de la Asociación Internacional de Hispanistas. Tomo VII. Estudios
Hispanoamericanos II: Birmingham: University of Birmingham Press.

Osorio Tejeda, Nelson. 1988. Manifiestos, proclamas y polémicas de la vanguardia literaria hispanoamericana. Caracas: Biblioteca Ayacucho.

Osorio Tejeda, Nelson. 1981. "Para una caracterización histórica del vanguardismo literario hispanoamericano". En: Revista Iberoamericana XLVII: 227-232.

Oviedo, JoséMiguel.2001.Historia de la literatura hispanoamericana. 3. Posmodernismo, Vanguardia, Regionalismo. Madrid: Alianza.

Piglia, Ricardo. 1987. "¿Existe la novela argentina? Borges y Gombrowicz". Espacios de crítica y producción VI: 13-15.

Piñón, Helio. 2000. Prólogo. En: Teoría de la vanguardia: 17.

Rússovich, Alejandro. 2011. "Schulz y Gombrowicz: una polaridad dialéctica". En: Abraham, Tomás. Tensiones filosóficas. Buenos Aires: Sudamericana. Recuperado de https://books.google.com. $\mathrm{mx} /$ books?isbn $=9500734648$. [Consulta: 31 de marzo de 2016].

Sábato, Ernesto. 1983. Prefacio. En: Ferdydurke: 7-13.

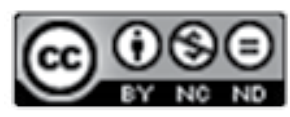

Este obra está bajo una licencia de Creative Commons

Reconocimiento-NoComercial-SinObraDerivada 4.0 Internacional. 
